JURNAL ILMIAH KEBIDANAN IMELDA

Vol.7, No.2, September 2021, pp.76-80

ISSN: 2597-7180 (Online), 2442-8116 (Print)

http://jurnal.uimedan.ac.id/index.php/JURNALKEBIDANAN

\title{
GAMBARAN PENGETAHUAN REMAJA PUTRI TENTANG BAHAYA KEPUTIHAN DI DUSUN SERBA GUNA DESA KARANG REJO KECAMATAN STABAT KABUPATEN LANGKAT TAHUN 2021
}

\author{
Debora Lestari Simamora
}

Universitas Imelda Medan, Indonesia

\begin{tabular}{l}
\hline Article Info \\
\hline Article history: \\
Received Sep 25, 2021 \\
Revised Sep 26, 2021 \\
Accepted Sep 28, 2021 \\
\hline
\end{tabular}

Keywords:

Knowledge

teenage Girl

Dangers of Vaginal Discharge

\begin{abstract}
Vaginal discharge is vaginal discharge that usually occurs every month, usually appears before menstruation or after menstruation or the fertile period. This study aims to determine the knowledge of young women about the dangers of vaginal discharge in the Serba Guna Hamlet, Karang Rejo Village, Stabat District, Langkat Regency in 2021. This research is descriptive using primary data obtained by distributing questionnaires. The population in this study was mostly young women in Dusun Serbaguna Langkat in 2021 using random sampling of 30 respondents. The results of the study from 30 respondents were that the majority had less knowledge as many as 15 respondents $(50 \%)$. Respondents' knowledge based on the majority age $<12-13$ years was 8 people $(26.6 \%)$ and knowledge based on the majority of information sources lacked 6 people (20\%). The conclusion of this study is the lack of internal and external genital hygiene of adolescent girls.
\end{abstract}

This is an open access article under the CC BY-SAlicense.

\section{Corresponding Author:}

Debora Lestari simamora,

Program Studi S1 Kebidanan,

Universitas Imelda Medan,

Jl. Bilal No. 52 Kelurahan Pulo Brayan Darat I Kecamatan Medan Timur, Medan - Sumatera Utara.

Email: Hilbramgavriel@gmail.com

\section{INTRODUCTION}

Keputihan adalah cairan atau lendir pekat yang mengalir dari vagina. Keputihan disebabkan jamur Candida, terutama Candida Albicans yang menginfeksi secara superficial atau terlokalisasi. Keputihan dapat disertai gejala atau tanpa ada gejala yang dirasakan, tetapi jika dilakukan pembiakan sekret vaginal akan terlihat jamur Kandida (Manan, 2011).

Jumlah keputihan yang normal sangat beragam dan cukup normal, seperti hal nya jumlah zat yang dikeluarkan dalam mulut (saliva) juga sangat beragam. Zat-zat yang dikeluarkan tidak hanya membuat vagina lembab, seperti yang diinginkan, tetapi juga menjaga kebersihan. Akan tetapi, dari waktu ke waktu peningkatan tersebut dapat membuat celana dalam wanita basah dan terasa mengganggu, tidak usah dirisaukan dan perawatan tidak di perlukan pengobatan (Liewellyn, 2005).

Sesuai dengan data kesehatan internasianal $75 \%$ wanita minimal pernah mengalami keputihan satu kali dalam hidupnya. Di negara Eropa misalnya, terdapat 25\% kasus wanita yang mengalami keputihan setiap tahunnya. Sementara itu, menurut data Family Carp International (1995) Amerika Serikat bahwa satu dari 20 remaja mengalami keputihan dengan jumlah penderita tertinggi pada usia 15-20 tahun (Proverawati-misroh, 2010). 
Banyak menganggap remeh terhadap terjadinya keputihan karena hal ini sudah menjadi rahasia umum. Keputihan yang kerap kali terjadi sebelum dan sesudah masa menstruasi ini memang sudah umum terjadi pada setiap individu perempuan. Namun demikian, dalam konteks ini kita harus juga memahami apakah biasa ataukah sebaliknya. Jika keputihan yang terjadi adalah keputihan biasa, maka hal itu tidak akan menyebabkan suatu gangguan. Namun sebaliknya, apabila keputihan tersebut adalah suatu ketidak normalan, maka bisa di pastikan kesehatan anda sedang terganggu. Dan hanya demikian bukan hanya sebagai suatu pertanda adanya gangguan, tetapi juga bisa menyebabkan gangguan kesehatan lain (Adi, 2011).

Keputihan yang terjadi adalah keputihan biasa, maka hal itu tidak akan menyebabkan suatu gangguan. Namun sebaliknya, apabila keputihan tersebut adalah suatu ketidaknormalan, maka bisa di pastikan kesehatan anda sedang terganggu. Dan hanya demikian bukan hanya sebagai suatu pertanda adanya gangguan, tetapi juga bisa menyebabkan gangguan kesehatan lain (Adi, 2011).

Dari survey awal yang peneliti lakukan di Dusun Serbaguna Langkat Tahun 2021. Dengan jumlah 1072 jiwa dan $169 \mathrm{KK}$, dimana diantaranya terdiri dari 132 remaja putri yang mana sekitar 80\% tidak mengerti tentang bahaya keputihan. Berdasarkan data diatas penulis berminat melakukan penelitian dengan judul "Gambaran Pengetahuan Remaja Putri Tentang Bahaya Keputihan di Dusun Serbaguna Desa Karang Rejo Kecamatan Stabat Kabupaten Langkat Tahun 2021”.

\section{RESEARCH METHOD}

Jenis penelitian yang digunakan adalah deskriptif, yaitu dengan menggunakan data primer yang dikumpulkan melalui pengisian kuesioner. Penelitian ini dilakukan di dusun serba guna desa karang rejo kecamatan stabat kabupaten dengan populasi sebanyak 30 responden dan pengambilan sample dengan mengunakan total sampling yaitu sebanyak 30 responden.

\section{RESULTS AND ANALYSIS}

\subsection{Hasil Univariat}

Setelah dilakukan penelitian terhadap 30 responden yang merupakan sampel dalam penelitian ini, maka diperoleh hasil sebagai berikut:

Tabel 1. Distrubusi Gambaran Pengetahuan Remaja Putri Tentang Bahaya Keputihan Di Dusun Serbaguna Langkat Tahun 2021 Berdasarkan Sumber Pengetahuan

\begin{tabular}{cccc}
\hline No & Tingkat Pengetahuan & F & \% \\
\hline 1 & Baik & 6 & 20 \\
\hline 2 & Cukup & 9 & 30 \\
\hline 3 & Kurang & 15 & 50 \\
\hline & Jumlah & $\mathbf{3 0}$ & $\mathbf{1 0 0}$
\end{tabular}

Berdasarkan tabel diatas dapat dilihat bahwa mayoritas tingkat pengetahuan remaja putri tentang bahaya keputihan adalah kurang sebanyak 15 responden (50\%) dan kelompok pengetahuan minoritas adalah baik sebanyak 6 responden $(20 \%)$.

Tabel 2. Distribusi Gambaran Pengetahuan Remaja Putri Tentang Bahaya Keputihan Di Dusun Serbaguna Langkat Tahun 2021 Berdasarkan Sumber Pendidikan

\begin{tabular}{|c|c|c|c|c|c|c|c|c|c|}
\hline \multirow{3}{*}{ No } & \multirow{3}{*}{ Pendidikan } & \multicolumn{6}{|c|}{ Kategori Pengetahuan } & \multirow{3}{*}{ Jumlah } & \multirow{3}{*}{$\%$} \\
\hline & & \multicolumn{2}{|c|}{ Baik } & \multicolumn{2}{|c|}{ Cukup } & \multicolumn{2}{|c|}{ Kurang } & & \\
\hline & & $\mathbf{F}$ & $\%$ & $\mathbf{F}$ & $\%$ & $\mathbf{F}$ & $\%$ & & \\
\hline 1 & SD & 1 & 3,3 & 1 & 3,3 & 2 & 6,7 & 4 & 13,3 \\
\hline 2 & SMP & 3 & 10 & 2 & 6,7 & 4 & 13,3 & 9 & 30 \\
\hline 3 & SMA & 2 & 6,7 & 5 & 16,6 & 8 & 26,6 & 15 & 50 \\
\hline 4 & Perguruan Tinggi & - & - & 1 & 3,3 & 1 & 3,3 & 2 & 6,7 \\
\hline & Jumlah & 6 & 20 & 9 & 30 & 15 & 50 & 30 & 100 \\
\hline
\end{tabular}

Berdasarkan tabel di atas dapat di lihat bahwa pengetahuan remaja putri berdasarkan pendidikan mayoritas kurang, pendidikan SMA sebanyak 8 responden $(26,6 \%)$ dan minoritas pengetahuan baik pada tingkat pendidikan SD sebanyak 1 responden $(3,3 \%)$. 
Tabel 3. Distribusi Gambaran Pengetahuan Remaja Putri Tentang Bahaya Keputihan Di Dusun Serbaguna Langkat Tahun 2021 Berdasarkan Sumber Umur

\begin{tabular}{|c|c|c|c|c|c|c|c|c|c|}
\hline \multirow{3}{*}{ No } & \multirow{3}{*}{ Umur } & \multicolumn{6}{|c|}{ Kategori Pengetahuan } & \multirow{3}{*}{ Jumlah } & \multirow{3}{*}{$\%$} \\
\hline & & \multicolumn{2}{|c|}{ Baik } & \multicolumn{2}{|c|}{ Cukup } & \multicolumn{2}{|c|}{ Kurang } & & \\
\hline & & $\mathbf{F}$ & $\%$ & $\mathbf{F}$ & $\%$ & $\mathbf{F}$ & $\%$ & & \\
\hline 1 & 10 & 1 & 3,3 & 1 & 3,3 & 3 & 10 & 5 & 16,6 \\
\hline 2 & $12-13$ & 2 & 6,7 & 4 & 13,3 & 8 & 26,6 & 14 & 46,6 \\
\hline 3 & $17-18$ & 2 & 6,7 & 2 & 6,7 & 2 & 6,7 & 6 & 20 \\
\hline 4 & $17-19$ & 1 & 3,3 & 2 & 6,7 & 2 & 6,7 & 5 & 16.6 \\
\hline & nlah & 6 & 20 & 9 & 30 & 15 & 50 & 30 & 100 \\
\hline
\end{tabular}

Berdasarkan tabel di atas dapat di lihat bahwa dari 30 responden terdapat mayoritas remaja putri yang berumur 12-13 tahun berpengetahuan kurang sebanyak 8 responden $(26,6 \%)$ minoritas remaja putri yang berumur 10 tahun berpengetahuan baik sebanyak 1 responden $(3,3 \%)$.

Tabel 4. Distribusi Gambaran Pengetahuan Remaja Putri Tentang Bahaya Keputihan Di Dusun Serbaguna Langkat Tahun 2021 Berdasarkan Sumber Informasi

\begin{tabular}{|c|c|c|c|c|c|c|c|c|c|}
\hline \multirow{3}{*}{ No } & \multirow{3}{*}{ Sumber Informasi } & \multicolumn{6}{|c|}{ Kategori Pengetahuan } & \multirow{3}{*}{ Jumlah } & \multirow{3}{*}{$\%$} \\
\hline & & \multicolumn{2}{|c|}{ Baik } & \multicolumn{2}{|c|}{ Cukup } & \multicolumn{2}{|c|}{ Kurang } & & \\
\hline & & $\mathbf{F}$ & $\%$ & $\mathbf{F}$ & $\%$ & $\mathbf{F}$ & $\%$ & & \\
\hline 1 & Petugas Kesehatan & 3 & 10 & 6 & 20 & 6 & 20 & 15 & 50 \\
\hline 2 & Keluarga & 1 & 3,3 & 1 & 3,3 & 5 & 16,6 & 7 & 23,3 \\
\hline 3 & Media Masa & 2 & 6,7 & 2 & 6,7 & 4 & 13,3 & 8 & 26,6 \\
\hline & Jumlah & 6 & 20 & 9 & 30 & 15 & $\mathbf{5 0}$ & 30 & 100 \\
\hline
\end{tabular}

Berdasarkan tabel di atas dapat di lihat bahwa pengetahuan remaja putri berdasarkan sumber informasi mayoritas berpengetahuan kurang pada remaja putri yang mendapat sumber informasi dari petugas kesehatan sebanyak 6 responden $(20 \%)$, dan minoritas berpengetahuan baik pada remaja putri yang mendapat sumber informasi dari keluarga sebanyak 1 responden $(3,3 \%)$.

\subsection{Pembahasan Pengetahuan}

Berdasarkan hasil penelitian pada tabel 1 dapat di lihat bahwa mayoritas gambaran pengetahuan remaja putri tentang bahaya keputihan adalah kurang sebanyak 15 responden (50\%) dan kelompok pengetahuan minoritas adalah baik sebanyak 6 responden (20\%). Dari tabel di atas tampak bahwa gambaran pengetahuan remaja putri tentang bahaya keputihan masih kurang. Dari data di atas peneliti menarik kesimpulan bahwa gambaran remaja putri tentang bahaya keputihan masih rendah.

Hasil penelitian ini sejalan dengan penelitian February (2016) dengan Hasil penelitian ini menunjukan bahwa remaja putri yang berpengetahuan cukup sebesar $61,7 \%$, remaja putri yang bersikap positif sebesar $56,8 \%$, remaja putri yang berperilaku positif sebesar $50,6 \%$, remaja putri yang berpengetahuan baik serta bersikap positif sebesar 68,0\%, dan remaja putri yang berpengetahuan cukup serta berperilaku baik sebesar $62 \%$

Menurut Notoatmodjo (2010) menyatakan bahwa pengetahuan itu merupakan kesiapan atau ketersediaan untuk bertindak dan bukan merupakan suatu tindakan atau aktifitas, akan tetapi merupakan suatu predisposisi tindakan atau perilaku. Dan pengetahuan merupakan hasil pengindraan manusia atau hasil tahu seseorang terhadap objek melalui indera yang dimilikinya (mata, hidung, telinga dan sebagainya). Dengan sendirinya, pada waktu penginderaan menghasilkan pengetahuan tersebut sangat dipengaruhi oleh intensitas perhatian dan persepsi terhadap objek. Sebagian besar pengetahuan seseorang diperoleh melalui indera pendengaran (telinga) dan indera penglihatan (mata).

\section{Pendidikan}

Berdasarkan hasil penelitian pada tabel 2 dapat di lihat bahwa pengetahuan remaja putri berdasarkan pendidikan mayoritas kurang pada gambaran pendidikan SMA sebanyak 8 responden $(26,6 \%)$ dan minoritas pengetahuan baik pada tingkat pendidikan SD sebanyak 1 responden $(3,3 \%)$.

Dari data di atas peneliti menarik kesimpulan bahwa gambaran pendidikan seseorang mempengaruhi tingkat pengetahuan di mana semakin tinggi gambaran pendidikan seseorang maka makin mudah menerima sumber informasi sehingga banyak pula pengetahuan yang di peroleh sehingga remaja putri dapat meningkatkan kesehatannya. 


\section{Umur}

Dapat di ketahui bahwa gambaran pengetahuan responden berdasarkan umur di dapat hasil bahwa mayoritas remaja putri berumur 12 -13 tahun berpengetahuan kurang sebanyak 8 responden (26,6\%). Dan minoritas remaja putri berumur 10 tahun berpengetahuan baik sebanyak 1 responden $(3,3 \%)$.

(Syaiful Bahri, 2002) mengatan bahwa semakin meningkatnya umur seseorang semakin dewasa pula cara pikirnya dan ini akan lebih mengukurkan pendapat yang mengatakan bahwa kecerdasan dan umur mempunyai hubungan yang sangat erat, semakin dewasa seseorang semakin abstrak cara berfikirnya sedangkan perkembangan berfikir seseorang dari konkret yang abstrak tidak dapat di pisahkan dari intelegensinya. Dalam hal ini penulis menarik kesimpulan bahwa hasil yang diperoleh di lapangan tidak sesuai dengan teori yang ada. Karena usia tidak mempengaruhi tingkat pengetahuan seseorang.

\section{Sumber Informasi}

Dapat di ketahui bahwa gambaran pengetahuan responden berdasarkan sumber informasi di dapat hasil bahwa mayoritas remaja putri memperoleh sumber informasi dari petugas kesehatan berpengetahuan kurang sebanyak 6 responden (20\%), minoritas remaja putri memperoleh informasi dari keluarga berpengetahuan baik sebanyak 1 responden $(3,3 \%)$.

Menurut Notoatmodjo (2003) sumber informasi merupakan alat bantu yang akan membantu dalam melaksanakan atau melakukan penyuluhan agar pesan kesehatan dapat di sampaikan. Sumber informasi kesehatan yang dapat mempunyai peran yang tepat dalam meningkatkan pengetahuan seseorang. Dalam hal ini penulis menarik kesimpulan bahwa hasil yang di peroleh di lapangan tidak sesuai dengan teori yang ada karena remaja putri mencari sumber informasi dari orang-orang sekelilingnya.

Hasil penelitian sejalan dengan dengan penelitian evi tri muyani, 2017 ini menunjukkan bahwa tingkat pengetahuan remaja putri dipengaruhi oleh sumber informasi yang diperoleh dan pendidikan terakhir orang tua. Sebagian besar responden mendapatkan informasi dari media media elektronik (TV, Radio, Hp, dll) yaitu sebanyak 77 responden $48(55,8 \%)$. Di SMK ini tidak diajarkan materi tentang pendidikan kesehatan reproduksi remaja terutama keputihan. Oleh karena itu remaja putri harus mandiri untuk mencari informasi lebih tentang kesehatan reproduksi terutama keputihan

\section{CONCLUSION}

Dari hasil penelitian mengenai gambaran pengetahuan remaja putri tentang bahaya keputihan di Dusun Serbaguna Desa Karang Rejo Kecamatan Stabat Kabupaten Langkat Tahun 2021, maka diambil kesimpulan sebagai berikut:

1. Dari 30 responden yang diteliti didapat mayoritas responden mempunyai pengetahuan kurang sebanyak 15 responden $(50 \%)$ dan minoritas remaja putri berpengetahuan baik sebanyak 6 responden (20\%).

2. Dari 30 responden yang di teliti di dapat mayoritas responden mempunyai tingkat pendidikan SMA berpengetahuan kurang sebanyak 8 responden $(26,6 \%)$ dan minoritas remaja putri mempunyai tingkat pendidikan SD berpengetahuan baik sebanyak 1 responden $(3,3 \%)$.

3. Dari 30 responden yang di teliti di dapat mayoritas responden berumur 12-13 tahun 8 responden $(26,6 \%)$ dan minoritas responden berumur 10 tahun dengan berpengetahuan baik sebanyak 1 responden $(3,3 \%)$.

4. Dari 30 responden yang di teliti di dapat mayoritas responden memperoleh sumber informasi dari petugas kesehatan dengan berpengetahuan kurang sebanyak 6 responden (20\%) dan minoritas responden mendapat sumber informasi dari keluarga dengan berpengetahuan baik sebanyak 1 responden $(3,3 \%)$.

\section{REFERENCES}

Ali, Ansori. 2008. Psikologi Remaja Perkembangan Peserta Didik. Jakarta: Bumi Aksara.

Depkes, Poltekes. 2010. Kesehatan Remaja Problem Dan Solusinya. Jakarta: Salemba Medika.

Liewellyn. 2005. Setiap Wanita. Jakarta. Delapratasa.

M, Manan. 2011. Miss V. Jokyakarta. Buku biru.

Muhammad, Adi. 2011. Tips Jitu Bisa Hamil. Jogyakarta. Buku Biru.

Notoatmodjo, S. 2005. Promosi Kesehatan Teori Dan Aplikasi. Jakarta: Rineka Cipta.

Notoatmodjo, S, 2007. Kesehatan Masyarakat Ilmu Dan Seni. Jakarta: Rineka Cipta.

Notoatmodjo, S, 2010. Metodologi penelitian Kesehatan. Jakarta: Rineka Cipta.

Winaris, Wahyu. 2010. Tanya Jawab Kesehatan Untuk Remaja. Jokyakarta: Tunas Publishing.

http:// WWW. Compas. Keputihan. com.

http:// WWW. Google Bahaya Keputihan Bagi Remaja Putri. com.

http://WWW. Google Gejala Keputihan. Com 


\section{BIOGRAPHIES OF AUTHORS}

\begin{tabular}{|l|l|}
\hline & $\begin{array}{l}\text { Debora Lestari Simamora, Gelar D-III diperoleh dari Akademi Kebidanan Imelda } \\
\text { Medan, Jurusan Kebidanan pada tahun 2009. Gelar Sarjana diperoleh dari Poltekes } \\
\text { Kemenkes RI Medan, Jurusan Bidan Pendidik Tahun 2011. Magister Kesehatan } \\
\text { diperoleh dari Universitas Sumatera Utara, Jurusan Kesehatan Reproduksi pada tahun } \\
\text { 2017. Saat ini aktif sebagai dosen tetap di Prodi D-III Kebidanan Universitas Imelda } \\
\text { Medan. }\end{array}$ \\
\hline
\end{tabular}

